\title{
Homossexualidade: um debate necessário no Ensino Fundamental?
}

\author{
Artur Livônio Tavares de Sampaio ${ }^{1}$; Iarê Andrade Lucas ${ }^{2}$
}

Resumo: Estudo sobre a homossexualidade, trazendo visões jurídicas, psicológicas e da medicina. Catalogando o que diz a legislação a respeito e o que poderia ser feito a luz das políticas públicas. Posto que, as políticas públicas são o canal propiciador da introdução de tal conteúdo nas escolas. Pesquisa baseada nos ensinamentos de autores, como Fernão Barbosa Riezo e Maria Luiza Silveira Teles, experientes no tema, que engrandecem a discussão e desmistificam preconceitos.

Palavras chave: Educação Sexual; Homossexualidade; Políticas Públicas.

\section{Homosexuality: an essential debate in Elementary Education}

\begin{abstract}
Study on homosexuality, bringing visions legal, psychological and medical . Cataloging what the law says about it and what could be done in light of public policies. Since, public policies are propitious channel introducing such content in schools. Research based on the teachings of authors such as Jonathan Barbosa Riezo and Maria Luiza Silveira Teles, experienced in the topic, which enlarge the debate and demystify prejudices.
\end{abstract}

Keywords: Educação Sexual; Homossexualidade; Políticas Públicas.

\section{Introdução}

Estudando a "homossexualidade", trata-se da condição de alguns indivíduos que sentem atração "permanente" (não meramente ocasional) por pessoas do mesmo sexo. Esta condição, surge ainda na infância e sua origem pode ter traços biológicos (hormonais), psicológicos (fases do desenvolvimento) ou educacionais (a criação), a depender da pessoa. O termo, etimologicamente, vem do grego, onde "homo" significa "igual".

\footnotetext{
${ }^{1}$ Advogado, mestrando em Educação, especialista em Direito Processual Civil (URCA-Crato), Direito das Famílias (URCA-Crato) e Direito Penal e Processual Penal (ESMAPE-Recife), atuando principalmente nas áreas: Trabalhista; Cível; de Família; e do Consumidor (arturlivonio@yahoo.com.br);

${ }^{2}$ Graduado em História pela Universidade Regional do Cariri - URCA, Especialista em História Moderna e Contemporânea pela Pontifícia Universidade Católica de Minas Gerais - PUC-MG, Mestre em História Social pela Universidade Federal do Rio de Janeiro - UFRJ, Doutor em História pelo Programa História, Ideologias e Culturas Políticas Contemporâneas da Universidade de Sevilla/Espanha. Professor Efetivo Adjunto da Universidade Regional do Cariri. E-mail: iareluc@gmail.com.
} 
Primeiramente, será feita uma pesquisa de como o Direito aborda tal tema, catalogando o que diz a legislação a respeito, bem como a jurisprudência (posição dos tribunais), trazendo visões jurídicas, psicológicas e da medicina.

Depois, o estudo se focará na relação entre o tema da homossexualidade e das políticas públicas. Buscando o que poderia ser feito a luz das políticas públicas. Em outras palavras, debater se: a homossexualidade deve fazer parte da grade de disciplina dos estudantes; e, caso deva, como se deve introduzir este tema nas escolas, bem como, qual idade é mais adequada para isso.

Posto que, se for para colocar este assunto para os alunos, as políticas públicas são o canal, indiscutivelmente, mais eficaz da introdução de tal conteúdo nas escolas, não poderia estudar homossexualidade, distante do das políticas públicas.

Esta pesquisa será bibliográfica, devido o reduzido tempo para feitura da mesma. Pesquisa baseada nos ensinamentos de autores, como Fernão Barbosa Riezo e Maria Luiza Silveira Teles, experientes no tema, que engrandecem a discussão e desmistificam preconceitos.

Assunto que está em bastante evidência no momento e que merece ser discutido com cuidado, para trazer uma melhor forma de educar e, ao mesmo tempo, de não discriminar quem é homossexual. Assim se torna evidente a sua total relevância para o estudo educacional.

\section{Evolução do Conceito de Homossexualidade no Direito}

A Organização Mundial de Saúde (OMS) é o órgão responsável pela publicação do CID10 (Classificação Internacional de Doenças), que é a lista de todas as doenças, com um código (numeração) para cada uma. Assim, com este código, os profissionais da saúde podem se referir as doenças sem precisarem verbalizar o nome da enfermidade. Lá estão contidas o que a OMS, até então, considera doença.

Desta maneira, o homossexualismo já fez parte do rol de doenças previstas no CID10. Mas, com o passar do tempo, viu-se que não se trata de doença, sendo assim, foi retirado do CID 10. E por isso, deixou de ser nominado de "homossexualismo" e passou a ser "homossexualidade". Esclarecendo melhor: 


\begin{abstract}
O vocábulo "homossexual" tem origem etimológica grega, significando "homo" ou "homoe" a ideia de semelhança, igual, análogo, ou seja, homólogo ou semelhante ao sexo que a pessoa almeja ter. A prática da homossexualidade acompanha a história da humanidade. Porém, hodiernamente, deixou de ser tratada como assunto "proibido", embora ainda esteja permeada de preconceitos sociais. Assim como na sociedade, no campo científico, o conceito de homossexualismo também sofreu alteração. Em 1985, deixou de constar a homossexualidade no art. 302do Código Internacional de Doenças - CID - como uma doença mental. Na última revisão, de 1995, o sufixo "ismo", que significa doença, foi substituído pelo sufixo "dade", que significa modo de ser. A estimativa da ABGLT - Associação Brasileira de Gays, Lésbicas, Bissexuais, travestis e Transexuais - é de que a parcela homossexual da população brasileira atinja hoje a marca de 17,9 milhões de pessoas.
\end{abstract}

(RIEZO, 2011, p. 533)

A psicologia, além da medicina, estuda a homossexualidade, chegando à conclusão de que é ainda na infância onde se define a "condição sexual" do indivíduo. Por isso, é imprescindível uma educação adequada, principalmente neste período, em virtude de ser momento da "formação da personalidade". Sendo recomendado até um acompanhamento de um psicólogo, por ser um período em que poderia surtir algum efeito (não se manifestar a homossexualidade), devido a personalidade ainda está em formação. Afinal, a atuação de um psicólogo em alguém que já adentrou na adolescência, será meramente paliativa, onde apenas ensinará o sujeito a conviver melhor com aquela "condição sexual", sem chance de mudança. Como bem explica:

\begin{abstract}
Assim, a ação corretiva do educador deverá começar, não na adolescência, mas na infância, quando se percebem atitudes feminóides persistentes no menino e virilóides na menina. Uma orientação dos pais por parte de um especialista, assim como uma terapia com a criança, poderá evitar futuros males. Na adolescência, porém, a terapia poderá ajudar apenas em alguns poucos casos. Na maioria, a sexualidade do indivíduo, na direção oposta, já se terá firmado. De qualquer forma, como o homossexual é, quase sempre, um neurótico, não deixa de se beneficiar com a terapia, embora não se possa tornar heterossexual. A terapia ajuda o indivíduo a aceitar a sua realidade e viver a sua sexualidade, da maneira que lhe é possível, sem ansiedade e sem culpa.

(TELES, 1985, p. 109-110)
\end{abstract}

Vale destacar, que o psicanalista francês, Jacques-Marie Émile Lacan, diz ainda, que as crianças que forem criadas (adotadas) por um "casal gay", não sofrerão prejuízo na sua formação psicológica. É que, por mais que o homem faça o papel da regra e a mãe do afeto, estes papeis se manifestam também nos casais homossexuais, sendo um mais amável e o outro mais racional.

Com o Direito, não foi diferente, no que diz respeito a homossexualidade. Diante do avanço da ciência e da existência social de relações homoafetivas, novas interpretações jurisprudências (decisão dos tribunais superiores) foram aparecendo. E assim, o tema ganhou 
Id on Line Revista Multidisciplinar e de Psicologia

Id on Line Multidisciplinary and Psycology Journal

espaço dentro do "Direito de Família", passando, inclusive, a merecer ser visto de modo isolado, como: "Direito Homoafetivo".

O Estado brasileiro, por longos anos, só considerava como "família", aquela oriunda do casamento. Mas isso não significa que os outros tipos de família não existissem, apenas não possuíam proteção legal. E, se existem faticamente, não poderiam continuar a margem da lei, ao total desamparo.

Por muitos anos, juridicamente, a única forma de família era a proveniente do "casamento" (matrimonial), sem possibilidade de dissolução (divórcio), só sendo possível o "desquite" (atualmente: separação judicial). Nesta época, a maioria das mulheres eram "donas de casa" (não trabalhavam fora de casa), devido a isso, o casamento era o que lhe manteria financeiramente, após a morte de seus pais. Em consequência disso, as que se "desquitavam", eram chamadas de "desquitadas" e viviam sendo alvo de preconceito constante, umas até se prostituíam, já que não poderiam mais casar com mais ninguém.

Mas em 26 de dezembro de 1977, foi sancionada a Lei n. 6.515, que ficou conhecida como "Lei do Divórcio". Com esta lei, as pessoas passaram a poder descasarem, romper o vínculo matrimonial, enfim, se divorciarem. Somado a isso a Constituição Federal de 1988 trouxe a "união estável”, em seu art. 226, fazendo com que os casais que vivem como se casados fossem, sem serem casados, passassem a ter proteção semelhante a dada pelo casamento. Isso gerou imensa repercussão na sociedade, pois o próprio Estado estaria admitindo outra forma de família, sem ser somente a matrimonial, mas também vinda da "união estável".

Outra mudança no ordenamento jurídico sobre tal tema, surgiu em 7 de agosto de 2006, trazida pelo art. 5, II, da Lei n. 11.340 (Lei Maria da Penha), quando colocou o "afeto" como principal fator caracterizador de uma "família" e não mais o "patrimônio" como fazia o Código Civil de 1916 e o de 2002: "comunidade formada por indivíduos que são ou se consideram aparentados, unidos por laços naturais, por afinidade ou por vontade expressa".

Neste diapasão de mudanças sociais e legislativas, muitos "casais gays" passaram a buscar proteção, ingressando com ações na justiça, pedindo o reconhecimento da "união estável" ou do "direito de adotar". Com isso o judiciário foi obrigado a julgar, mesmo na omissão legislativa sobre tal tema, posto que o art. 4, do Decreto-Lei n. 4.657, de 4 de setembro de 1942 (Lei de Introdução às Normas do Direito Brasileiro), obriga os juízes a decidirem, mesmo quando não existir lei, fazendo uso dos costumes, da analogia e dos "Princípios Gerais 
do Direito”. Por isso, em maio de 2011 houve a decisão dos ministros do Supremo Tribunal Federal (STF), julgando tanto a "Ação Direta de Inconstitucionalidade" (ADI) n. 4277, quanto a "Arguição de Descumprimento de Preceito Fundamental" (ADPF) n. 132, reconhecendo a união estável para "pessoas do mesmo sexo".

Portanto, não há motivos plausíveis para que as "pessoas do mesmo sexo" não recebam proteção do Estado. $\mathrm{O}$ art. 226 da CF/88 diz que a família é a base da sociedade, não limitando seu conceito a apenas "homem e mulher". E a Constituição só traz a expressão "homem e mulher", quando fala de "união estável" no art. 226, § 3, da CF/88, mesmo assim, de modo exemplificativo e não taxativo. Ademais, encontra-se no art. 3, IV, da CF/88, como um dos “objetivos fundamentais da República Federativa do Brasil", a promoção ao bem de todos, "sem preconceitos de origem, raça, sexo, cor, idade e quaisquer outras formas de discriminação".

\title{
Adequação da Política Pública que visa educar sobre a Homossexualidade
}

Existe a polêmica se a homossexualidade deve ou não ser abordada dentro da sala de aula e, mesmo para quem defende que deve, se discute a partir de que idade (ou fase do desenvolvimento da personalidade) se daria esta instrução.

Como se sabe, cada fase do desenvolvimento psicossocial de Freud merece uma atenção especial (fase oral; anal; fálica; de latência; e genital), tanto dos pais, quanto dos professores na escola. Então, tem coisas próprias de cada idade e da própria fase:

\begin{abstract}
Freud mostrou que a criança possui seus impulsos e atividades sexuais, desde o início da existência; trá-los com ela ao mundo e deles emerge a chamada sexualidade normal dos adultos, mediante uma evolução significativa, através de múltiplas fases: a fase oral, anal, fálica, de latência e genital. No desenvolvimento da personalidade infantil, portanto, a libido também se desenvolve, em suas diversas conquistas, com repercussões profundas e extensas no terreno psicológico, sendo que determinados acontecimentos, em cada uma destas fases, podem bloquear a evolução do indivíduo, fazendo com que ele se fixe num destes períodos ou mesmo regrida. Só depois de ter resolvido com êxito uma certa sequência dos usos pré-genitais da libido, a sexualidade da criança se transforma gradualmente em uma transitória genitalidade infantil, que se tornará logo latente até que seja de novo despertada pelas forças da adolescência. (TELES, 1985, p. 75)
\end{abstract}

Falando, por exemplo, da adolescência, é o momento em que vadiados conflitos surgem na mente. Os conselhos dos pais antes vistos como "verdades absolutas", na adolescência são 
questionados e colocados em paralelo com o que escuta dos amigos ou companheiros amorosos. Os adolescentes querem se afirmar fisicamente e "interiormente" (emocionalmente), mas biologicamente estão com as faces cheias de acne (espinhas) e o emocional com insegurança, devido a inexperiência sexual e afetiva. Dito de uma melhor forma:

O jovem necessita se afirmar, se fazer valer aos olhos dos companheiros e, para isto, é necessário romper com os pais, que o fazem lembrar a "vergonhosa" situação de dependência da infância. O grupo familiar terá, portanto, de sofrer. A intenção não é rejeitar a família, mas agir independentemente dela aumenta e preserva o seu prestígio entre os companheiros. (TELES, 1985, p. 102)

A questão da sexualidade é algo que envolve a adolescência, quando os hormônios estão bem acentuados, devido a libido. Por isso, em virtude deste aguçamento do interesse sexual, pode aparecer o que se chama popularmente como "troca troca". Pela carência e o desejo intenso, alguns garotos, por exemplo, penetram o ânus um do outro. Isso não faz com que se tornem homossexuais, tratando-se de algo normal, que pode ocorrer nesta idade. Assim sendo:

Em educação sexual é importante não transmitir valores diferentes para o rapaz e a moça, criando antagonismos e revolta. É útil lembrar que o sexo não é senão uma causalidade biológica e que a pessoa humana deve ser o objetivo primordial da educação. Na adolescência costuma aparecer, também, um determinado tipo de atividade sexual que é um pseudo-homossexualismo (mais corretamente chamado de homossexualidade). Essa atividade não indica nenhuma perversão e é, costumeiramente, um estágio para a heterossexualidade. Ela aparece em vista de os jovens do mesmo sexo andarem sempre juntos, na época da puberdade, quando o interesse sexual é bastante aguçado, levando-os a experiências esporádicas, sem maiores consequências. $\mathrm{O}$ verdadeiro homossexualismo é configurado na infância e raramente alguma coisa (no sentido de mudar a configuração) pode ser feita nesta fase de amadurecimento sexual. Todo indivíduo é bissexual, psicologicamente. O desenvolvimento em determinada direção dependerá de uma educação correta, que forneça ao ser em formação o modelo adequado. (TELES, 1985, p. 109)

A educação das mulheres e dos homens não deve ser diferente, o que é transmitido para uma menina, deve ser também transmitido para o menino. Afinal, as escolas trazem para os alunos, dados científicos, isentos de qualquer juízo de valor social. Os valores são incutidos, no ceio da família, não na escola. Na escola, como o próprio nome diz, se faz "escolarização". Desta forma, a "sexualidade" deve ser ensinada nas escolas, assim como temas ligados ao "homossexualismo", dentro da matéria Biologia, no capítulo de "Educação Sexual”. Só deve existir diferenciação da maneira e do nível de informação, a depender da idade, respeitando assim cada fase do desenvolvimento. Não sendo o conteúdo algo igual pra todas as idades. 
Ademais, observa-se que , mesmo quando o tema da homossexualidade não estava em pauta nas políticas públicas, ainda assim, o assunto da sexualidade era abordado em séries mais avançadas. Não aumentará o número de pessoas homossexuais, o ato de se abordar nas escolas tal tema. Se fosse partindo somente por este raciocínio, não existiriam homossexuais no mundo, pois sempre se falou da sexualidade heterossexual e, mesmo assim, há a presença de número significativo de homossexuais.

E, como a própria expressão diz "Educação Sexual”, ensina para a vida, para a ação. A escola informa como é a biologia do homem, da mulher e do homossexual. Sem parcialidade, apenas desnudando a realidade, com dados científicos. Sendo que, tudo isso, do modo adequado para cada idade (a metodologia adotada e a quantidade de informação), sem pressa, tudo no tempo certo:

O problema do sexo e da educação sexual na adolescência é bastante diferente e de amplitude muito maior que na infância. Nesta fase, o indivíduo já raciocina claramente e se acostuma a lidar com ideias, hipóteses e deduções. Por um prisma, porém, a atitude dos educadores deve continuar a ser a mesma adotada antes, isto é, de naturalidade e sinceridade. Os valores com relação ao sexo, os adolescentes vão adquirir em casa, enquanto que as informações, que agora deverão ser mais amplas e profundas, devem ser dadas, preferivelmente, por especialistas. Enquanto os educadores ainda discutem se a educação sexual deve ou não ser dada aos jovens, um bombardeio de informações e estímulos chega até eles por todos as vias de comunicação. Enquanto os pais vacilam em fornecer aos filhos conhecimentos indispensáveis sobre o assunto, e reagem indignados diante dos padrões sexuais da atualidade, os jovens, dia a dia, contestam mais os valores passados e assumem a sua sexualidade, fazendo opções neste terreno que não é senão para os antigos (sobrecarregados de preconceito) um terreno particular, especial e cruciante. A tensão sexual em que vive o adolescente é hoje muito maior do que aquela dos jovens de algumas décadas atrás. Primeiro, porque o preparo profissional exige que ele adie o casamento para além da adolescência; segundo, porque o estímulo é muito mais intenso. Isso configura uma nova realidade que exige, por parte dos educadores, uma retificação de valores. Continuar negando essa verdade e fugir de discutir o assunto abertamente com os jovens, e de ajudá-los com a compreensão e o apoio, relegandoos a um perigoso abandono, é arriscar-se a surpresas desagradáveis. (TELES, 1985, p. 108)

Portanto, é interessante que os alunos tomem conhecimento do assunto, para, independentemente de serem heterossexuais ou homossexuais, poderem vivenciar a sexualidade com responsabilidade, fazendo, inclusive, uso de técnicas que evitem doenças e gravidez indesejada. 
Id on Line Revista Multidisciplinar e de Psicologia

Id on Line Multidisciplinary and Psycology Journal

\section{Considerações Finais}

Espera-se que o tema da homossexualidade seja tratado de modo mais aberto, sem preconceitos, posto que é algo que existe. Não é algo criado, como quem cria um objeto (cadeira, mesa etc).

Acredita-se que o leitor tenha assimilado um pouco do desenrolar histórico-jurídico da homossexualidade no Brasil. Como também, mesmo que sucintamente, o que a psicologia e a medicina dizem a respeito.

Contudo, de nada adiantaria as ciências definirem ou buscarem a origem da homossexualidade, caso as pessoas não recebessem uma educação adequada. Deste modo, é pensando assim, que se busca uma política pública que realmente concretize os objetivos mais nobres do termo educação.

Portanto, para que este conteúdo seja introduzido nas escolas, o caminho é por meio das políticas públicas, que viabilize a transmissão deste conteúdo pelo MEC. Dentro da disciplina de Biologia, no item "Educação Sexual", a partir da adolescência. Desta forma, a "sexualidade" deve ser ensinada nas escolas, assim como temas ligados ao "homossexualismo", dentro da matéria Biologia, no capítulo de "Educação Sexual". Só deve existir diferenciação da maneira e do nível de informação, a depender da idade, respeitando assim cada fase do desenvolvimento. Não sendo o conteúdo algo igual pra todas as idades.

\section{Referências}

RIEZO, Fernão Barbosa. Família e sucessões: doutrina, legislação, jurisprudência e modelos. Petrópolis-RJ: Vale do Mogi Editora, 2011.

TELES, Maria Luiza Silveira. Uma introdução a psicologia da educação. 7. ed. Petrópolis: Vozes, 1985.

\section{Como citar este artigo (Formato ABNT):}

GOMES FILHO, A.S.; SANTOS, C.E.; SILVA, L.M. Sexo, Gênero, Sexualidade: Via(da)gens em Conceitos. Id on Line Revista Multidisciplinar e de Psicologia, Janeiro de 2017, vol.10, n.33, Supl 2. p. 37-46. ISSN: 19811179.

Recebido: 05/01/2017

Aceito: 09/01/2017 